\title{
Seasonal Prediction of Surface Air Temperature across Vietnam Using the Regional Climate Model Version 4.2 (RegCM4.2)
}

\author{
Tan Phan Van, ${ }^{1}$ Hiep Van Nguyen,, ${ }^{2}$ Long Trinh Tuan, ${ }^{1}$ Trung Nguyen Quang, \\ Thanh Ngo-Duc, ${ }^{1}$ Patrick Laux, ${ }^{3}$ and Thanh Nguyen Xuan ${ }^{1}$ \\ ${ }^{1}$ Department of Meteorology, VNU Hanoi University of Science, 334 Nguyen Trai, Thanh Xuan, Hanoi, Vietnam \\ ${ }^{2}$ Institute of Meteorology, Hydrology and Environment (IMHEN), 23/62 Nguyen Chi Thanh, Dong Da, Hanoi, Vietnam \\ ${ }^{3}$ Institute of Meteorology and Climate Research, Karlsruhe Institute of Technology (KIT, IMK-IFU), Kreuzeckbahnstrasse 19, \\ 82467 Garmisch-Partenkirchen, Germany
}

Correspondence should be addressed to Tan Phan Van; phanvantan@hus.edu.vn

Received 2 February 2014; Revised 4 April 2014; Accepted 16 April 2014; Published 18 June 2014

Academic Editor: Hann-Ming H. Juang

Copyright (C) 2014 Tan Phan Van et al. This is an open access article distributed under the Creative Commons Attribution License, which permits unrestricted use, distribution, and reproduction in any medium, provided the original work is properly cited.

\begin{abstract}
To investigate the ability of dynamical seasonal climate predictions for Vietnam, the RegCM4.2 is employed to perform seasonal prediction of $2 \mathrm{~m}$ mean (T2m), maximum (Tx), and minimum (Tn) air temperature for the period from January 2012 to November 2013 by downscaling the NCEP Climate Forecast System (CFS) data. For model bias correction, the model and observed climatology is constructed using the CFS reanalysis and observed temperatures over Vietnam for the period 1980-2010, respectively. The RegCM4.2 forecast is run four times per month from the current month up to the next six months. A model ensemble prediction initialized from the current month is computed from the mean of the four runs within the month. The results showed that, without any bias correction (CTL), the RegCM4.2 forecast has very little or no skill in both tercile and value predictions. With bias correction (BAS), model predictions show improved skill. The experiment in which the results from the BAS experiment are further successively adjusted (SUC) with model bias at one-month lead time of the previous run showed further improvement compared to CTL and BAS. Skill scores of the tercile probability forecasts were found to exceed 0.3 for most of the target months.
\end{abstract}

\section{Introduction}

Seasonal predictions are crucial for socio/economic planning as well as for disaster prevention. While short-range weather forecasts are valid for timescales of hours to days, seasonal predictions focus on long-term averages of meteorological variables [1]. Basic products of seasonal predictions are often given as monthly or seasonal mean values. Seasonal predictions can be performed by statistical and dynamical methods [2]. Statistical methods in which the predictions are conducted based on the statistical relationships between predictands (e.g., rainfall, temperature, and tropical cyclone activity) and predictors (e.g., geopotential height, sea surface temperature (SST), and soil moisture) have been widely applied [3-6]. The dynamical methods use numerical models to perform climate predictions. These models can predict the evolutions of the climate system for several months in advance [7]. The models can be in the form of general circulation models (GCMs) $[1,2]$ or regional climate models (RCMs) $[8,9]$. Dynamical methods using GCMs have shown advantages over statistical methods in predicting large-scale phenomena $[8,10-12]$. More specifically, with a relatively coarse horizontal resolution, the climate forecast system (CFS) has improved skill in forecasting the Nino-3.4 SST if compared to a statistical method in operation [10]. The CFS skill in representing SST results in reasonable predictions of large-scale circulation such as monsoon and El NiñoSouthern oscillation (ENSO) events [12-15]. One of the most important disadvantages of the GCMs is the high demand of computational costs. Therefore, the global models usually run with relatively coarse horizontal resolutions in which the effects of complex terrains as well as the impacts of subgrid scale features on local weather and climates cannot be well represented. Focusing on limited areas, RCMs can perform high-resolution seasonal predictions with relatively low computational costs. Running with higher resolutions, 
RCMs provide significant advantages over GCMs in generating small scale features such as convection $[8,9]$ or climate features over complex terrains $[16,17]$. Since RCMs run on limited areas and require GCM outputs as initial and boundary conditions, the quality of a RCM prediction depends not only on the RCM itself but also on the quality of the GCM forcing data. Furthermore, the prediction skill depends on RCM configurations such as domain size and frequency of time-dependent boundary forcing and applied physical parameterization schemes. Castro et al. [8] showed that the weather research and forecasting model (WRF) downscaling from CFS for North America adds value in precipitation prediction skill only during the early warm season in which CFS has good skill of predicting large-scale atmospheric circulation. According to Yuan and Liang [9], during the cold seasons over the United States, WRF reduces the errors of mean seasonal CFS precipitation by about $22 \%$. They also showed that the downscaling of WRF improves the forecast of extreme rainfall events.

With its complex topography, land surface conditions, long coastline, and influence by the Asian monsoon system, Vietnam has a complex climate. It is heavily influenced by mesoscale phenomena such as tropical disturbances embedded in the Intertropical conversion zone (ITCZ) and typhoons. During summer time (May to August), nearly the entire country experiences high-temperature conditions and extended hot spells except for the high mountain regions. During winter time, the North of Vietnam, including North Central, is affected by cold surges originating from the Siberian High, which might cause extreme cold spells. Rainfall from May to October contributes to about $80 \%$ of the annual total rainfall over the Northern and Southern Vietnam. In Central Vietnam, the rainy season lasts from August to December [18].

Seasonal prediction is one of the most important issues for agriculture as well as natural disaster prevention in Vietnam, especially in the context of climate change, in which unusual weather events are expected to occur more frequently. Operational seasonal predictions for Vietnam are currently conducted based on statistical methods only. Dynamical seasonal predictions with high-resolution RCMs for Vietnam are still not available. Recently, the RegCM model $[19,20]$ has been successfully used for climate studies in Vietnam including analysis of the seasonal and interannual variations of climate surface variables [21] and climate extremes over Vietnam [22]. Currently, CFS Version 2 (hereinafter referred to as CFSv2) output is available in real-time mode [10], which provides potential boundary conditions for RCMs.

In this work, the Regional Climate Model version 4.2 (RegCM4.2) is employed as a RCM. It is driven by CFSv2 data to perform downscaled seasonal predictions of monthly mean of 2-m (T2m), maximum (Tx), and minimum (Tm) air temperature over Vietnam during the years 2012 and 2013. The main objective is to evaluate the RegCM4.2 seasonal predictions over Vietnam. In the sequel of this paper, model configuration and experimental design are presented in Section 2. Results are shown in Section 3. A summary and discussions are given in Section 4.

\section{Model Configuration and Experimental Design}

2.1. Model Configuration. In this study, RegCM4.2, a primitive equation, hydrostatic, compressible, limited-area model $[19,20,23]$, is used. Model configuration is the same as in Ho et al. [22] which includes the biosphere-atmosphere transfer scheme (BATS), a nonlocal vertical diffusion boundary layer scheme [19], the Community Climate Model version 3 (CCM3) [24] radiation scheme, and Grell convective schemes [25]. There are 18 vertical $\sigma$-levels with 6 levels in the planetary boundary layer (below $850 \mathrm{mb}$ ). The top level pressure is $50 \mathrm{mb}$. The model runs with a single $36 \mathrm{~km}$ resolution domain (Figure 1(a)) centered at $11.5^{\circ} \mathrm{N}$ and $108.0^{\circ} \mathrm{E}$ with 145 and 131 grid points in West-East and South-North direction, respectively. Size of the lateral relaxation zone is 12 grid points. The lateral boundary conditions for the climatology simulation are provided by the NCEP Climate Forecast System version 1 reanalysis (CFSRv1) with a resolution of 0.5 degree. For the real-time seasonal predictions, the input data is from initial condition and forecasts every 6 hours of CFSv2 with a resolution of 1.0 degree.

In this study, the number of observation stations is restricted to 64 stations due to data availability (continuous series for 1981-2010). The data used for model verification were obtained from the Vietnam National HydroMeteorological Service (Figure 1(b)).

2.2. Experimental Design. RegCM4.2 is run for the period of 31 years from 1980 to 2010 with initial and boundary conditions from CFSRv1 (RegCM_CFSRv1) to construct the model climatology and to identify the model bias for grid cells with available observations. The model is run from $0000 \mathrm{Z} 01$ January 1980 to $0000 Z 01$ January 2011. The first year (1980) is used as model spin-up period and excluded from further analysis. Time series of grid cells corresponding to available observation stations are extracted. Thirty values of monthly mean for every variable from 30 years of model simulation are used to calculate the 33rd (q33) as well as the 66th (q66) percentiles for each month and grid cell of interest. The same procedure is applied to observed data.

For the prediction experiment, RegCM4.2 is driven by CFSv2 forecast (hereinafter referred to as RegCM_CFSv2) to conduct seasonal prediction for the period from February 2012 to November 2013. RegCM_CFSv2 is initialized every 7 days (4 times per month) from January 2012 to May 2013 and runs for a six-month period. The four ensemble members initialized each month (lead time is 0 ) are averaged to form an ensemble mean for the next 6 months, that is, with lead time from 1 to 6 . The experiment is considered as control run (hereinafter labeled CTL). The schematic diagram of the prediction experiment is shown in Figure 2.

The temperature prediction at a station is twofold, value, and tercile predictions. The tercile predictions are classified by three categories: below-normal, normal, and above-normal. In the tercile predictions, the observed terciles are obtained by comparison of the current observed monthly mean temperature with the observed q33 and q66 of the same month. The forecast terciles are assessed by comparing the current 


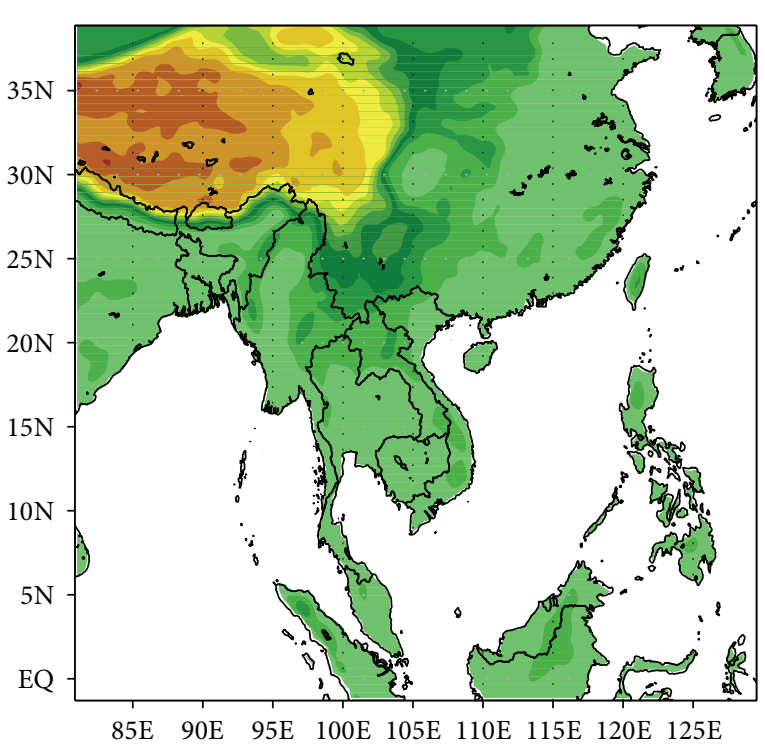

(a)

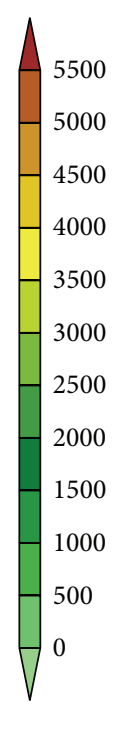

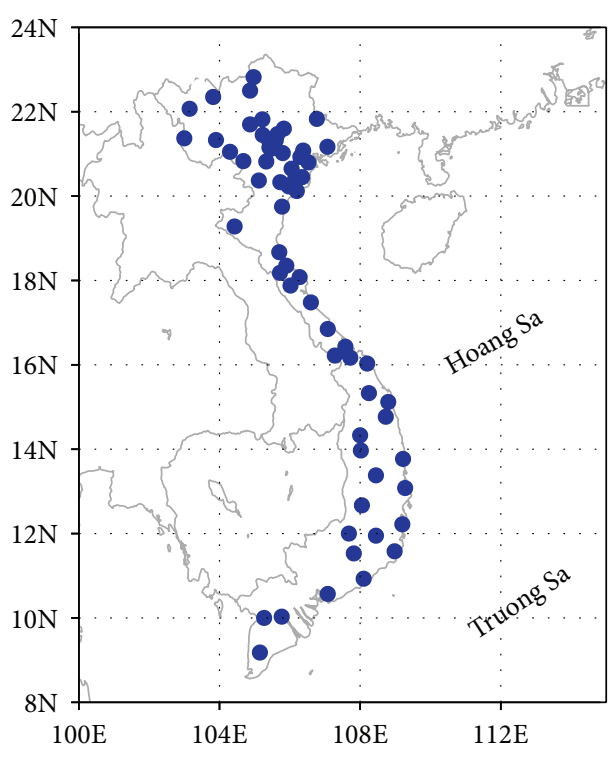

(b)

FIgURE 1: (a) The employed RegCM4.2 domain with model topography (m a.s.l.) and (b) locations of 64 meteorological stations used in this study.

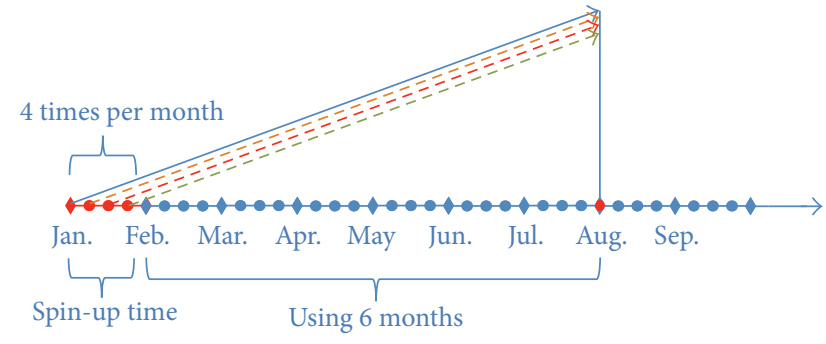

FIGURE 2: Prediction procedure, exemplarily shown for model initialization in January.

simulated monthly mean temperature with the simulated q33 and $\mathrm{q} 66$ of the same month.

To reduce the model systematic error (bias), two additional experiments are performed: (1) the model output is adjusted by the model climatology bias computed from 30year model simulation and observation at each station (BAS) and (2) the results from BAS runs are further successively adjusted with model bias at one month lead time of the previous run (SUC).

Since no CFS hindcasts are available to use as boundary conditions for the RegCM4.2, the RegCM_CFSRvl data were used to calculate the model climatology for bias correction. After doing bias correction there is still some model bias included in the predictions. The additional adjustment (SUC) is expected to further reduce the model bias. The forecast terciles for different target months and lead times are compared to the observed terciles. This allows assessing the model skill of the tercile predictions. The skill score (SS) is computed as a ratio of number of corrected station terciles. In the value predictions, observed (predicted) monthly means of $\mathrm{T} 2 \mathrm{~m}$,
Tx, and Tn are computed from observed (predicted) values. The predicted monthly mean is then compared with observed mean for model verification. In this work, a total of 780 months (i.e., 31 years $\times 12$ months of simulation with the CFSRvl data plus 17 months from January 2012 to May $2013 \times$ 4 cycles $\times 6$ months forecast) or 65 years of model runs were conducted to investigate the model performance in seasonal prediction for Vietnam, except the model runs within the initial months (lead time is 0 ).

\section{Results and Discussions}

3.1. Value Prediction of 2-m Temperature. The skill of both CFSv2 and downscaled seasonal predictions, that is, RegCM_CFSv2, is analyzed in the sequel. Observations and CFSv2 as well as RegCM_CFSv2 predictions of T2m are shown in Figure 3. It can be seen that CFSv2 generally underestimates temperatures for all lead times. This underestimation is higher for higher temperatures of about $25.0^{\circ} \mathrm{C}$ (Figure 3(a)). The RegCM_CFSv2 shows larger but more systematic cold biases (Figure 3(b)) compared to the CFSv2. The cold bias using RegCM was already revealed in previous studies (e.g., [26-28]) and for the Vietnam [21]. The systematic biases (linear deviations between the regression lines and the perfect agreement between RegCM_CFSv2 and observations) provide strong evidence for a successful application of a linear bias correction method. The Pearson correlation coefficients are increased on average (all lead times) from about 0.82 to 0.89 by downscaling. This implies that RegCM_CFSv2 provides some added skill to better represent the spatial patterns of observed temperature.

The performance of RegCM_CFSv2 in forecasting T2m is analyzed and illustrated in Figure 4. Without application 

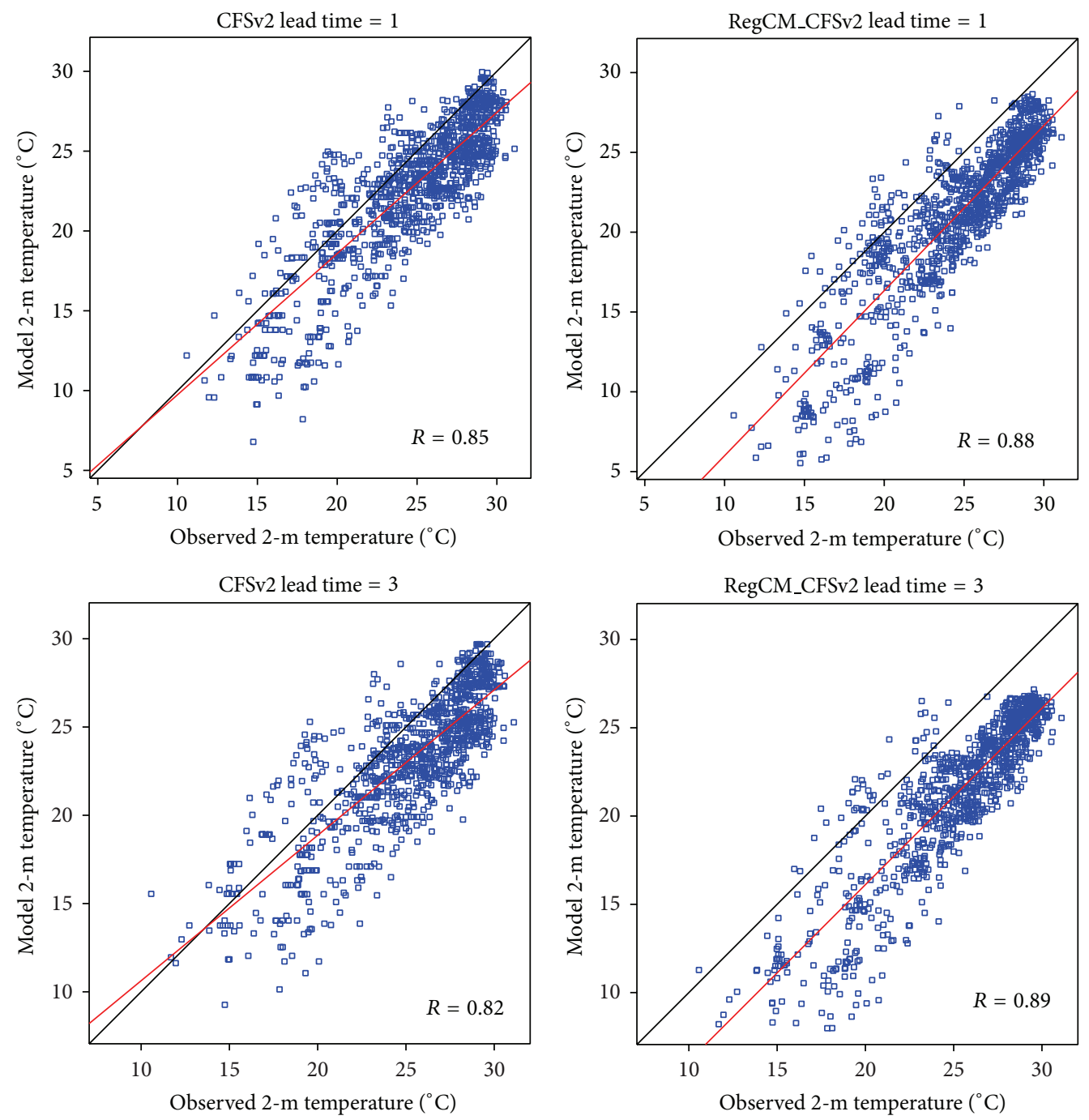

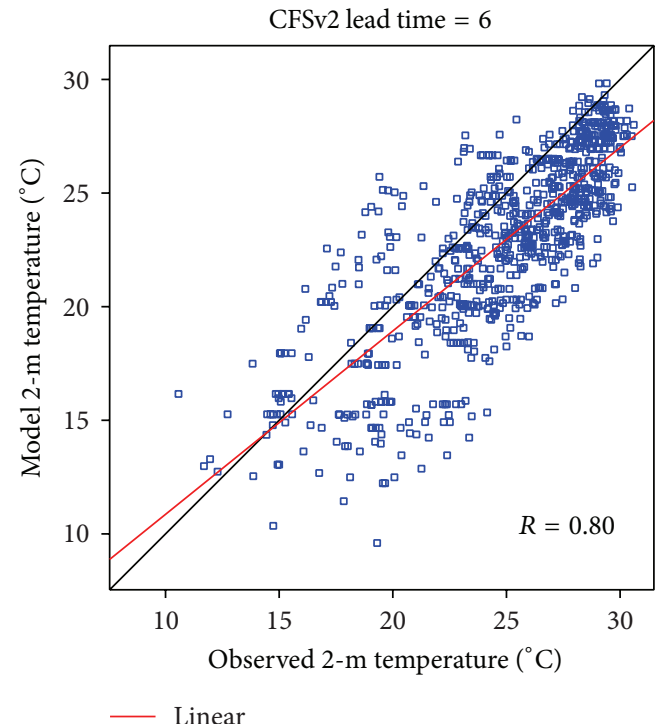

(a)

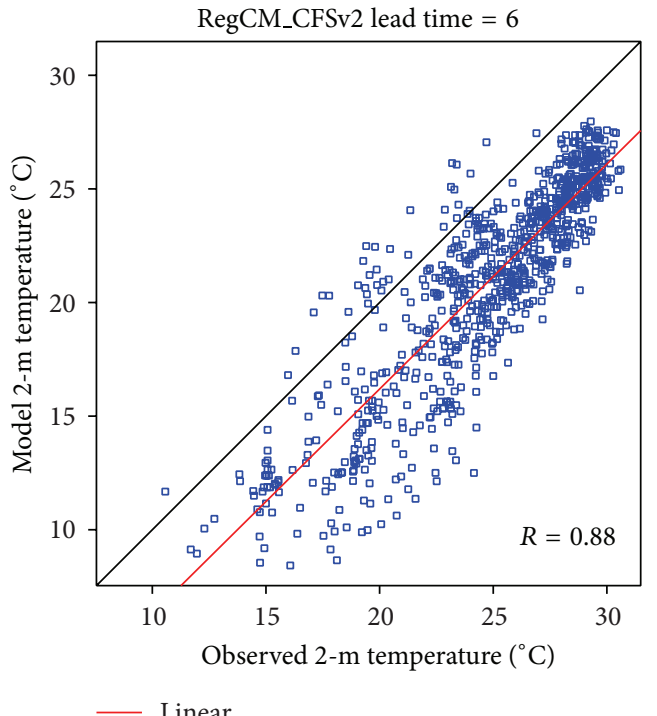

(b)

FIGURE 3: Relationship between observed and forecasted T2m $\left({ }^{\circ} \mathrm{C}\right)$ by CFSv2 (a) and RegCM_CFSv2 (b) for all stations, all target months from February 2012 to July 2013 with 1-, 3-, and 6-month lead times (top to bottom). Solid red line indicates the linear regression. Correlation coefficient $(R)$ is displayed at bottom right corner. The perfect regression line is presented by the black line. 


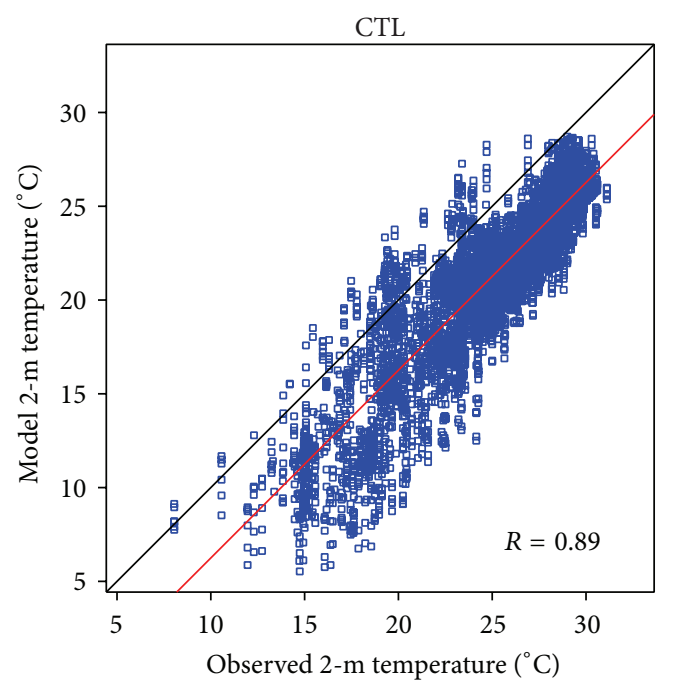

(a)

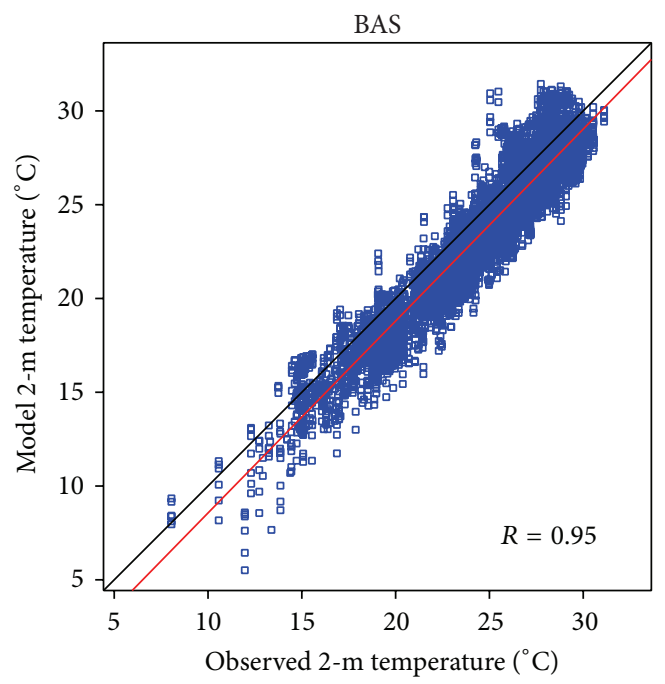

(b)

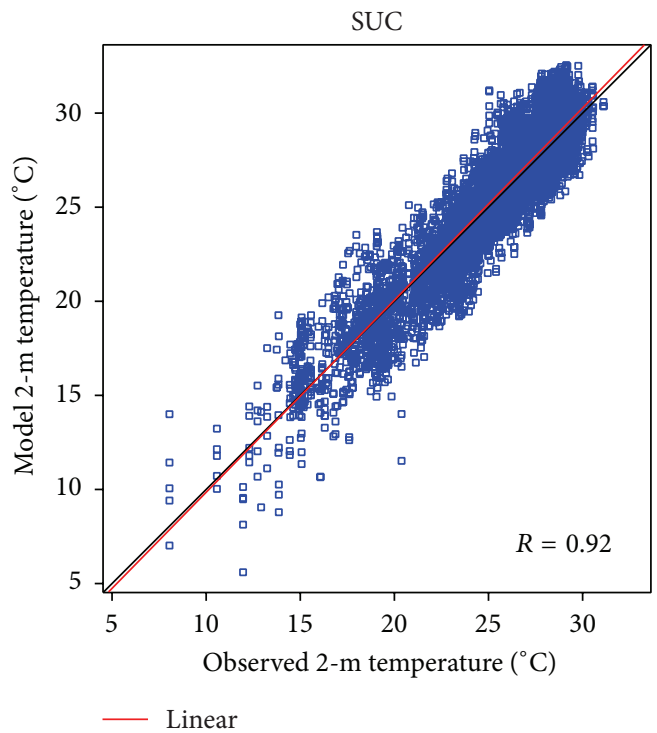

(c)

Figure 4: Relationship between observed and forecasted T2m $\left({ }^{\circ} \mathrm{C}\right)$ by RegCM_CFSv2 for all stations, all target months, and all lead times for experiments of (a) the control run-CTL, (b) the bias correction by model climatology-BAS, and (c) the successive adjustment of BAS with model bias at one month lead time of the previous run-SUC. The solid red line is the linear regression of the forecasted versus observed T2m. The perfect regression line is presented by the black line.

of bias correction, there exist significant cold biases in temperature forecast for the CTL (Figure 4(a)). Here, the cold biases are more pronounced for low temperatures (winter times). Besides the cold biases, the CTL also inhibits a large spread. For the observed $17.0^{\circ} \mathrm{C}$ value, for instance, the model forecasts range between $6.0^{\circ} \mathrm{C}$ and $20.0^{\circ} \mathrm{C}$ (Figure $4(\mathrm{a})$ ). With bias correction, the regression lines of the forecast (Figure 4(b), red) in the BAS experiments fit much closer to the perfect line (black) than in CTL. Spread as well as biases could be significantly reduced by application of BAS and SUC (Figures 4(b) and 4(c)). Although the cold bias is significantly reduced in BAS, the model forecast still shows a systematic cold bias represented by the regression lines.
Errors of predicted T2m for the different runs (CTL, BAS, and SUC) at different observation stations are shown in Figure 5. For the CTL run, the RegCM_CFSv2 shows negative biases, on average greater than $3.0^{\circ} \mathrm{C}$. The error is larger during winter $\left(>5.0^{\circ} \mathrm{C}\right)$ than during summer (approximately 2.0-3. $0^{\circ} \mathrm{C}$ ) and larger at stations located with high elevations (North of Vietnam and Central Highlands). There is only little impact from the lead times (Figures 5(a)-5(c), top). The significantly large errors of $3.0-5.0^{\circ} \mathrm{C}$ in CTL imply that the RegCM_CFSv2 without bias correction is not able to be used directly for seasonal forecasts.

As described in Section 2.2, the model climatology is estimated using outputs from RegCM_CFSRvl instead 
CTL lead time $=$

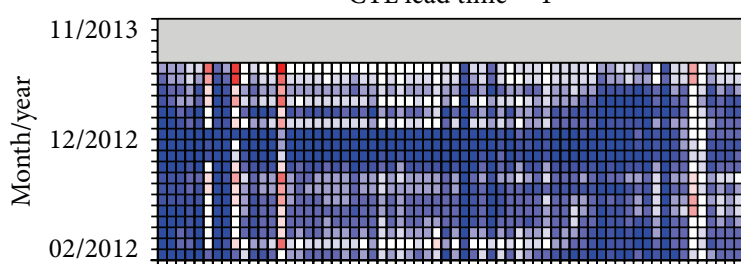

BAS lead time $=1$

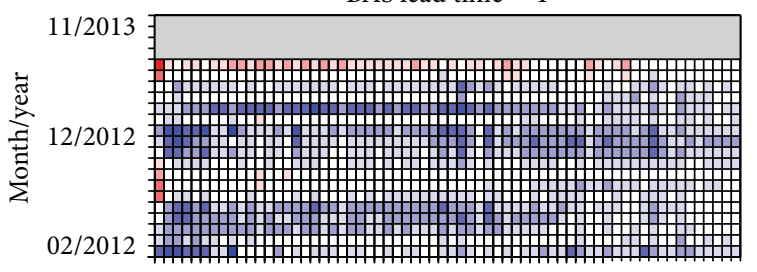

SUC lead time $=1$

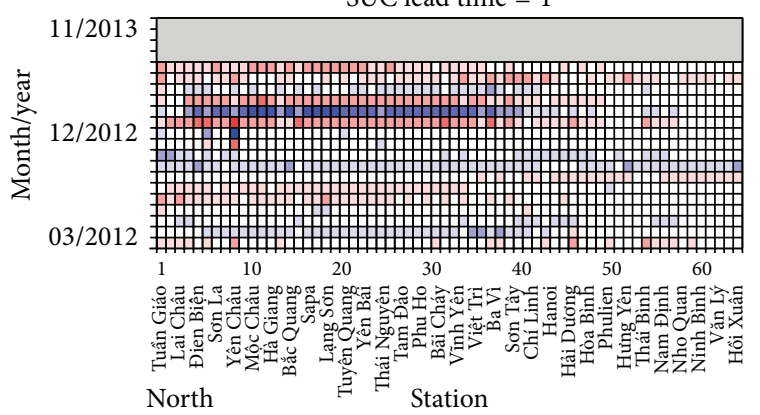

(a)

CTL lead time $=3$

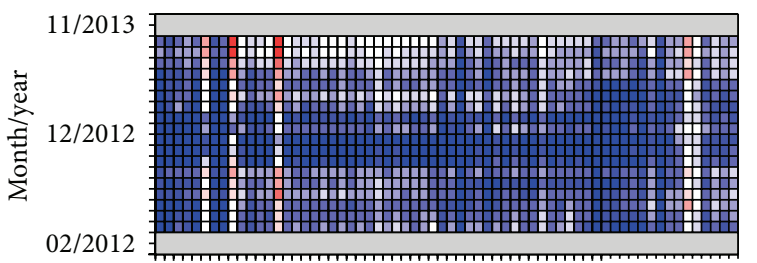

BAS lead time $=3$

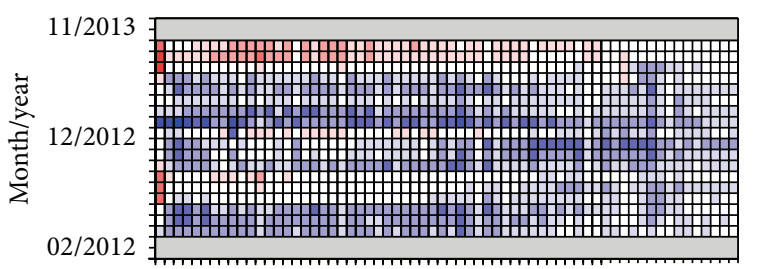

SUC lead time $=3$

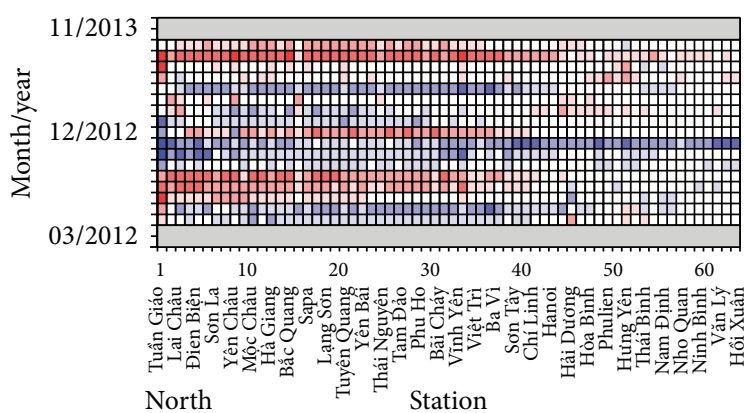

CTL lead time $=2$

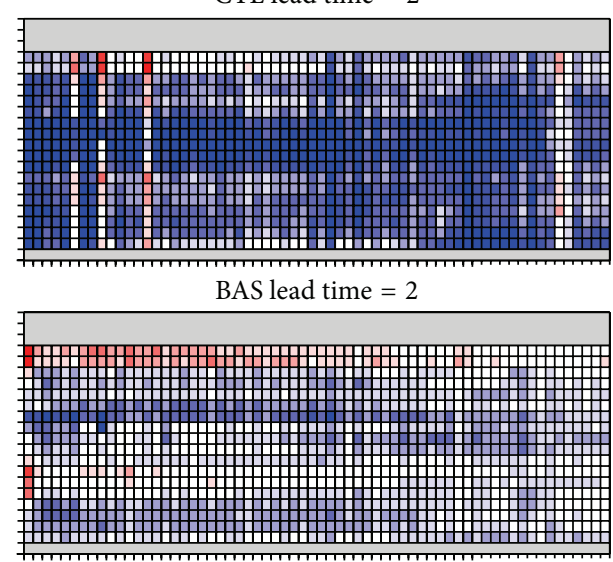

SUC lead time $=2$

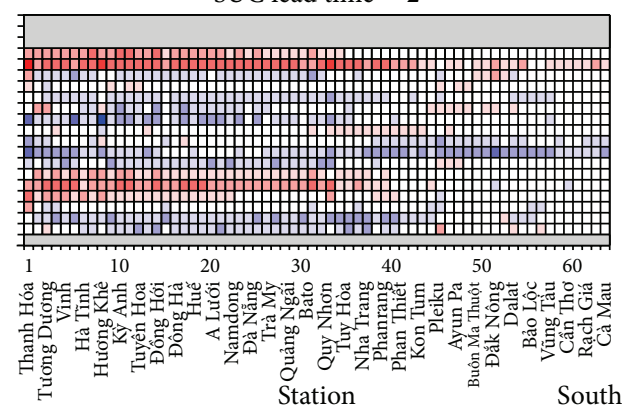

South
CTL lead time $=4$

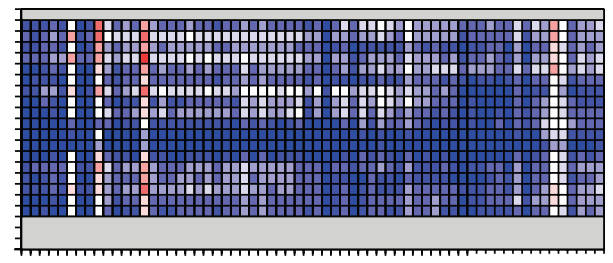

BAS lead time $=4$

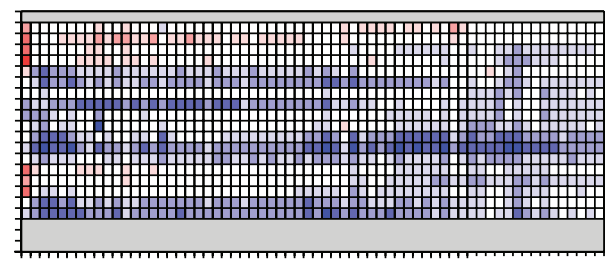

SUC lead time $=4$

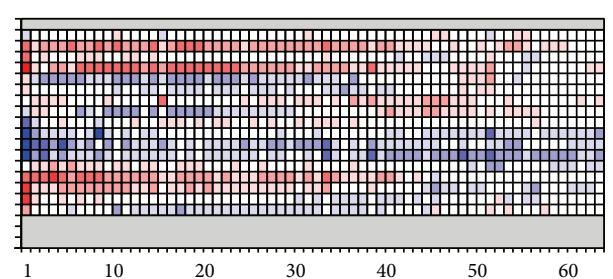

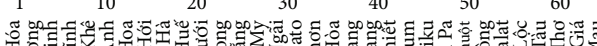

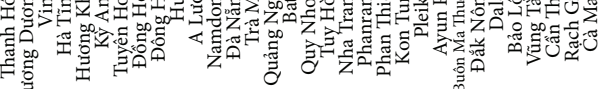

Station South

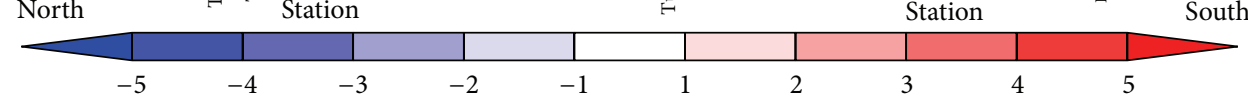

(b)

Figure 5: Continued. 


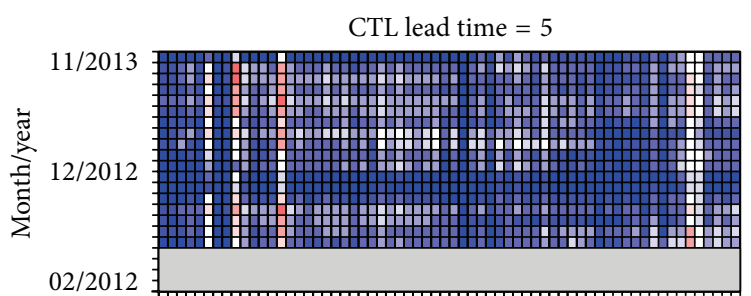

BAS lead time $=5$

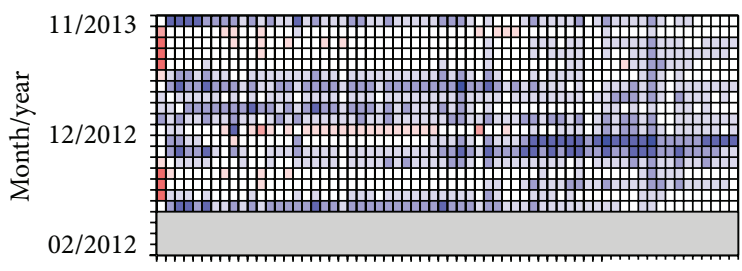

SUC lead time $=5$

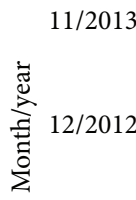

$03 / 2012$
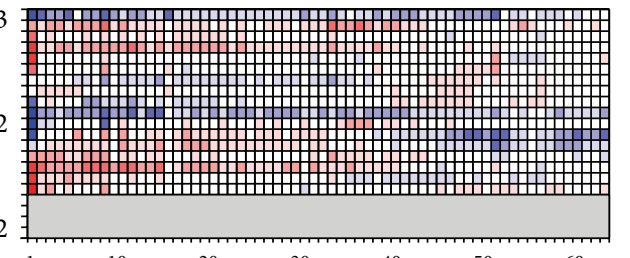

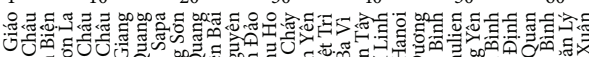

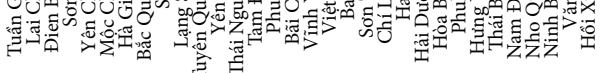

North

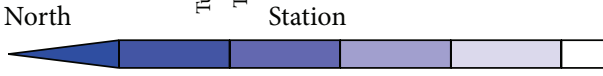

$-5$

$-3$

$-2$

(c)

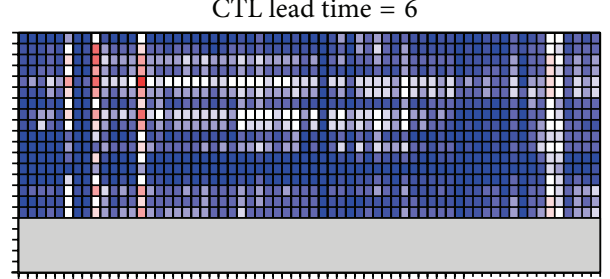

BAS lead time $=6$

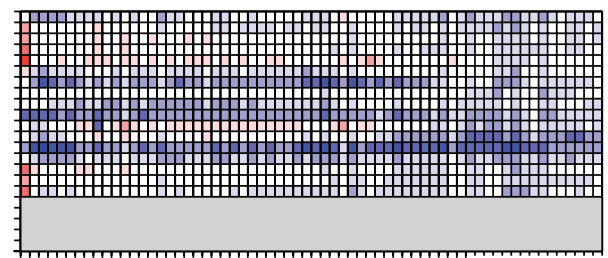

SUC lead time $=6$

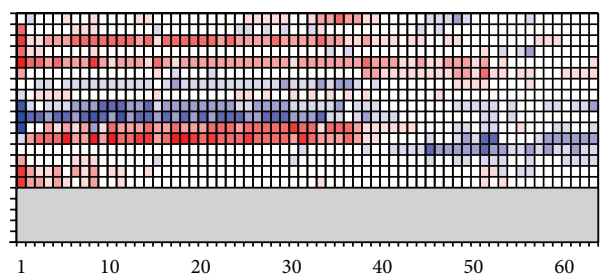

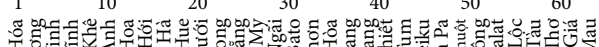

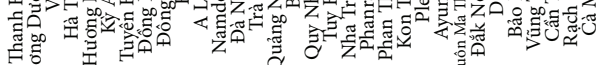

Station South

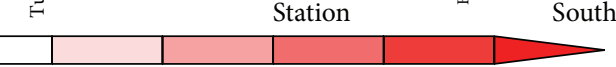

Figure 5: (a) The T2m forecast errors (model minus observation) at 64 stations for lead times of 1 and 2 months for the CTL (top), BAS (middle), and SUC (bottom) experiments. Vertical axis indicates target months. The numbers in horizontal axis indicate 64 stations in the order from North to South. The names of stations in the corresponding order are placed at the bottom of the figure. (b) Same as (a) but for lead times of 3 and 4 months. (c) Same as (a) but for lead times of 5 and 6 months.

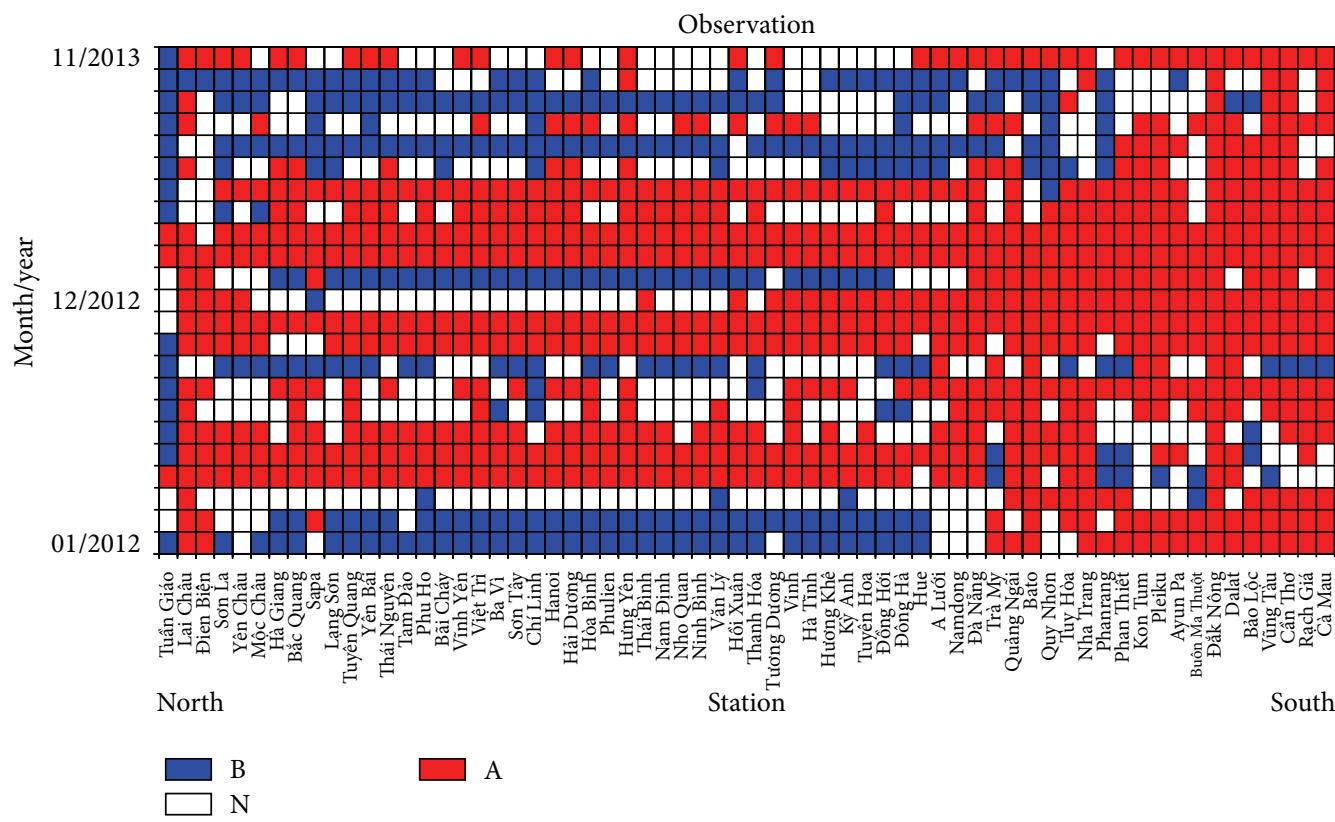

FIGURE 6: Observed tercile probability at 64 stations from January 2012 to November 2013. B (blue color), N (white color), and A (red color) indicate below-normal, normal, and above-normal probabilities, respectively. 
CTL lead time $=1$

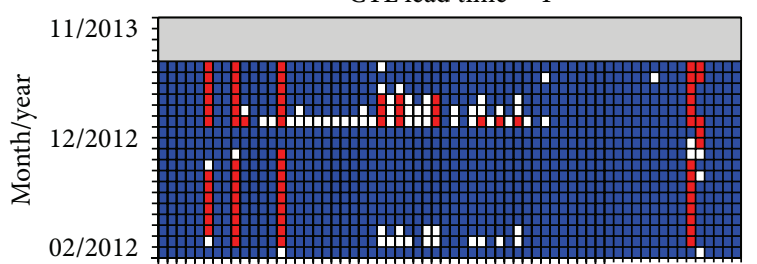

BAS lead time $=1$

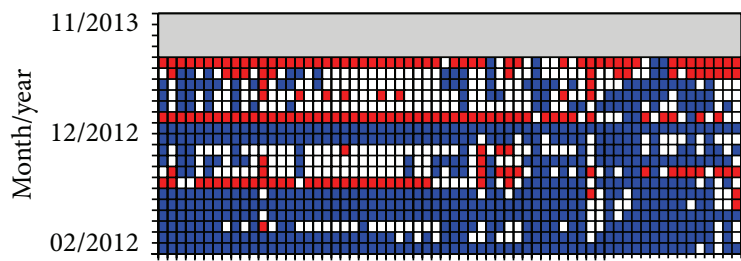

SUC lead time $=1$

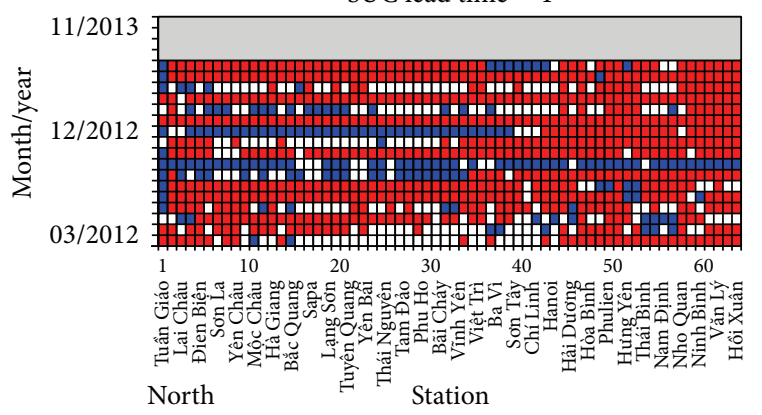

(a)

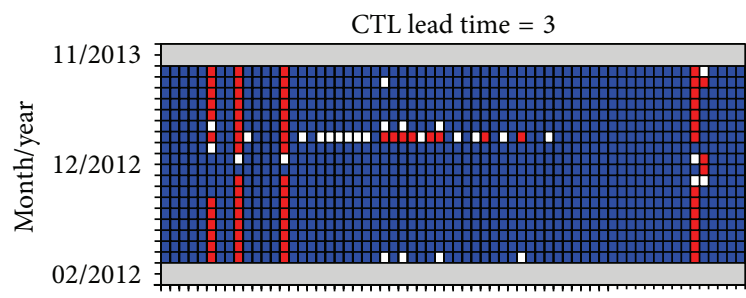

BAS lead time $=3$
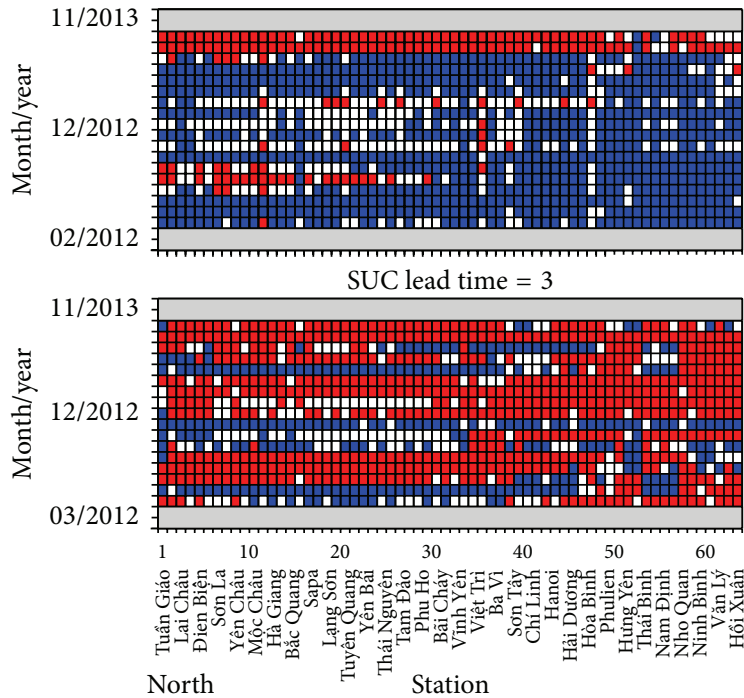

CTL lead time $=2$

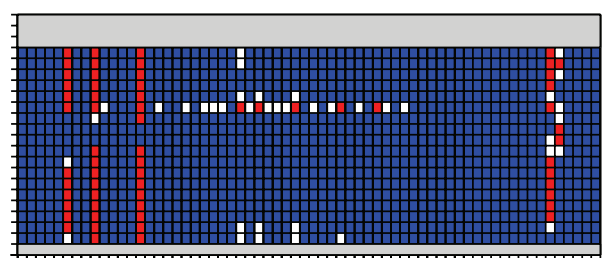

BAS lead time $=2$

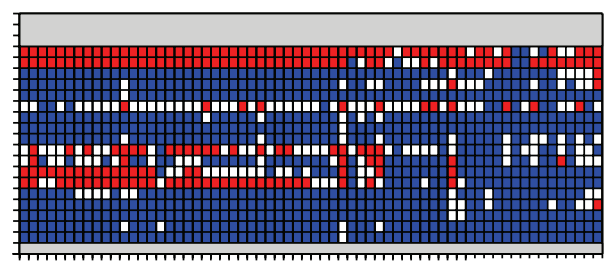

SUC lead time $=2$

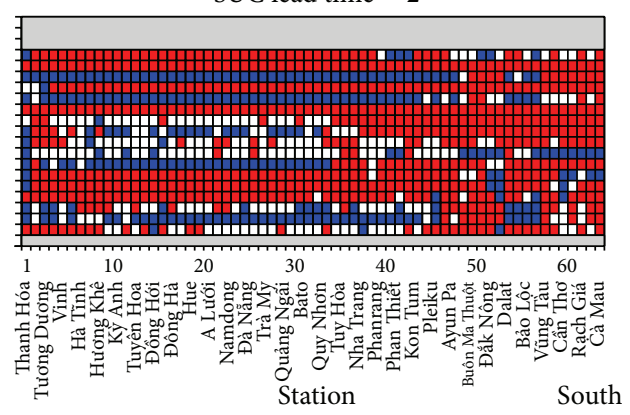

South

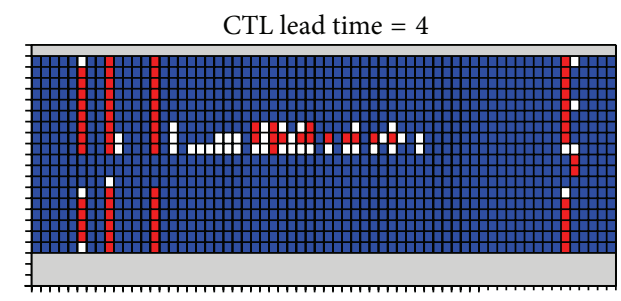

BAS lead time $=4$

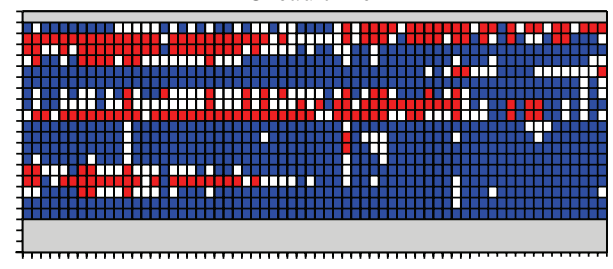

SUC lead time $=4$

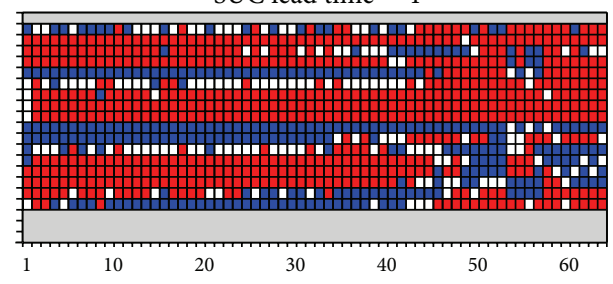

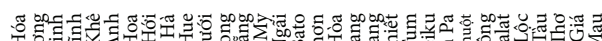

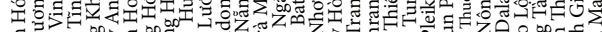

等

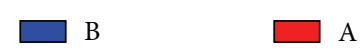

(b) 


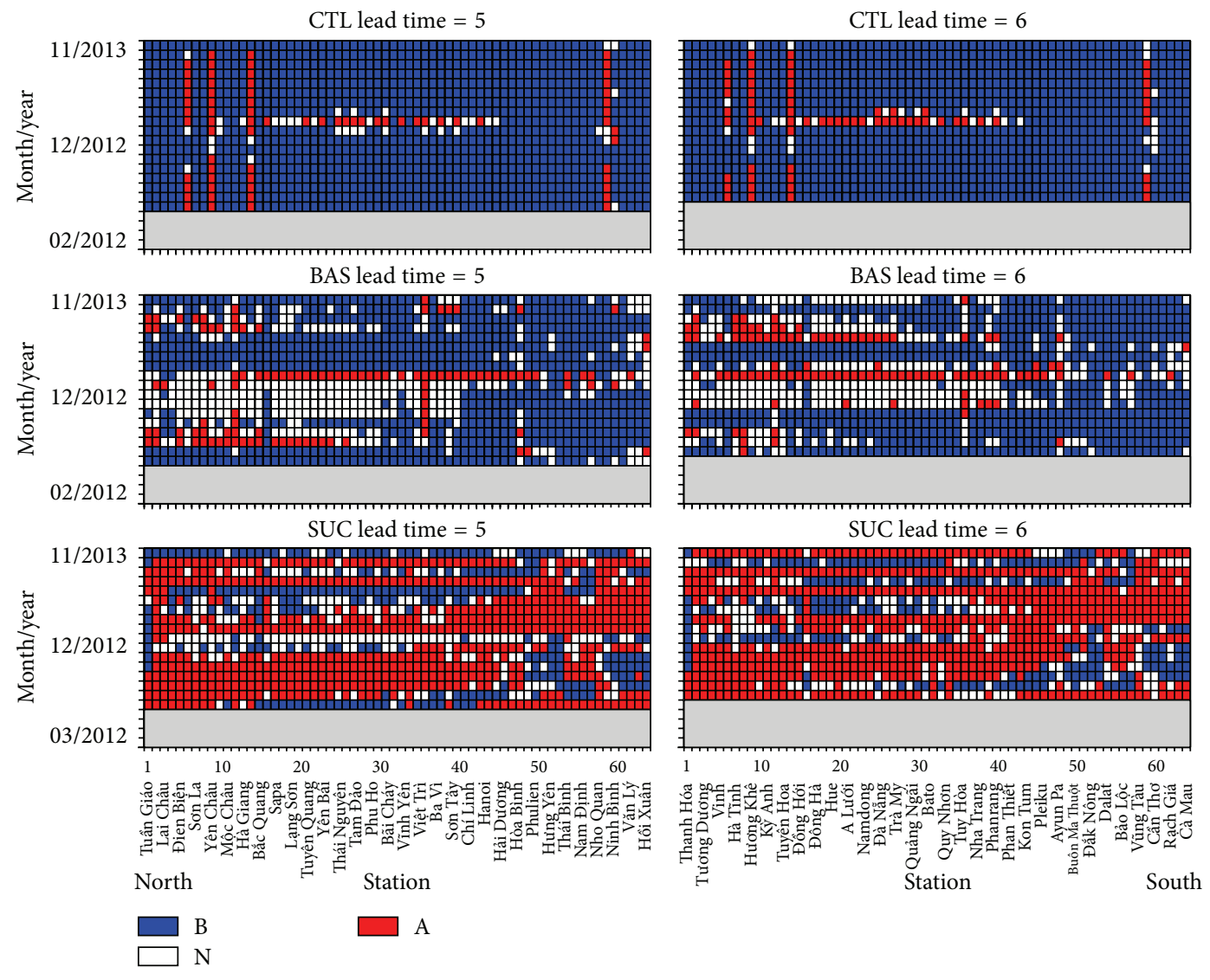

(c)

FIgURE 7: (a) Forecast tercile probabilities of T2m at 64 stations for lead times of 1 and 2 months for the CTL (top), BAS (middle), and SUC (bottom) experiments. Vertical axis indicates the target months. The numbers in horizontal axis indicate 64 stations in the order from North to South. The names of stations in the corresponding order are placed at the bottom of the figure. B (blue), N (white), and A (red) indicate below-normal, normal, and above-normal probabilities, respectively. (b) Same as (a) but for lead times of 3 and 4 months. (c) Same as (a) but for lead times of 5 and 6 months.

of RegCM4.2 run with the CFS hindcasts. CFSRv1 can be regarded as perfect boundary conditions; thus the RegCM_CFSRvl biases obtained are due to model errors from the RCM exclusively. The results show that RegCM_CFSRv1 represents well the observed temperatures over the period 1981-2010 (not shown), having correlation coefficients greater than 0.6 for most of the stations. The mean absolute errors (MAEs) and the root mean square errors (RMSEs) range between $2.0^{\circ} \mathrm{C}$ and $4.0^{\circ} \mathrm{C}$. There are pronounced systematic cold biases of simulated $\mathrm{T} 2 \mathrm{~m}$ with monthly mean biases at all stations ranging from about $-1.5^{\circ} \mathrm{C}$ to $-3.5^{\circ} \mathrm{C}$. The cold bias of RegCM model is again in agreement with Phan et al. [21].

In the BAS experiment, cold biases are noticeably reduced. The absolute errors are reduced to less than $2.5^{\circ} \mathrm{C}$ at almost all stations. About $50 \%$ of the stations have absolute errors of less than $1^{\circ} \mathrm{C}$ (Figures 5(a)-5(c), middle). Likewise for the CTL, the errors do not significantly increase with lead time. The cold biases in BAS at almost all stations and lead times (Figures 5(a)-5(c), middle) underpin the need for improved correction methods. With further successive correction method (SUC), as described in Section 2, the overall cold bias is reduced (Figure 4(c)). Comparing to BAS, the errors at stations for all lead times and all target months (Figures 5(a)-5(c), bottom) are reduced, particularly at Southern stations.

Concerning the dependence of the prediction errors on different regions of Vietnam, it can be seen that prediction errors are larger in the North of Vietnam compared to the Central and South parts of Vietnam for all experiments (Figure 5). It is speculated that the complex terrain (higher relative deviations from the elevation used in the RCM) as well as larger seasonal variation of temperature in Northern Vietnam is causing the larger errors. Further analysis is required but beyond the scope of this paper.

3.2. Tercile Prediction of 2-m Temperature. Figure 6 shows the observed terciles at 64 stations for the different target months. It is found that, during the period 2012-2013, most of the Southern stations experience above-normal probabilities, whereas the RegCM_CFSv2 usually predicts belownormal probabilities without application of any bias correction (Figure 7, top). This leads to predominantly zero skill 


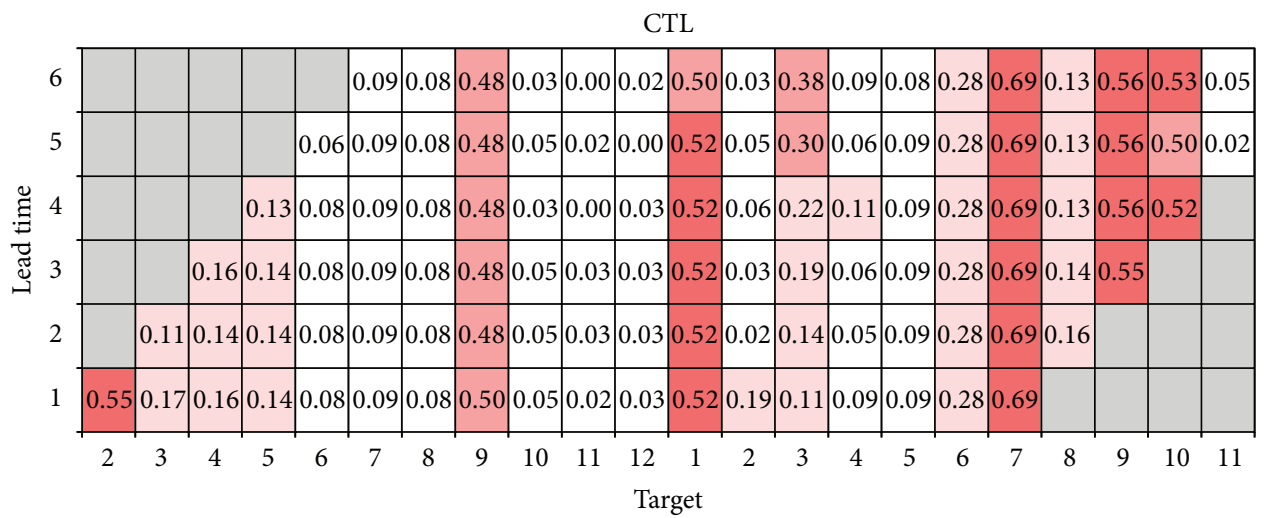

(a)

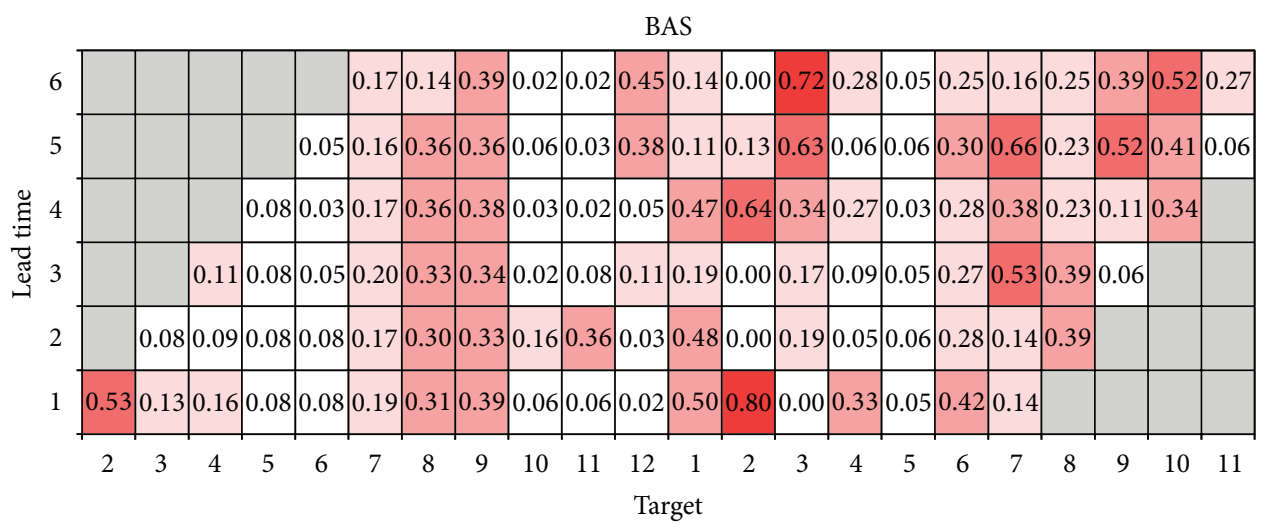

(b)

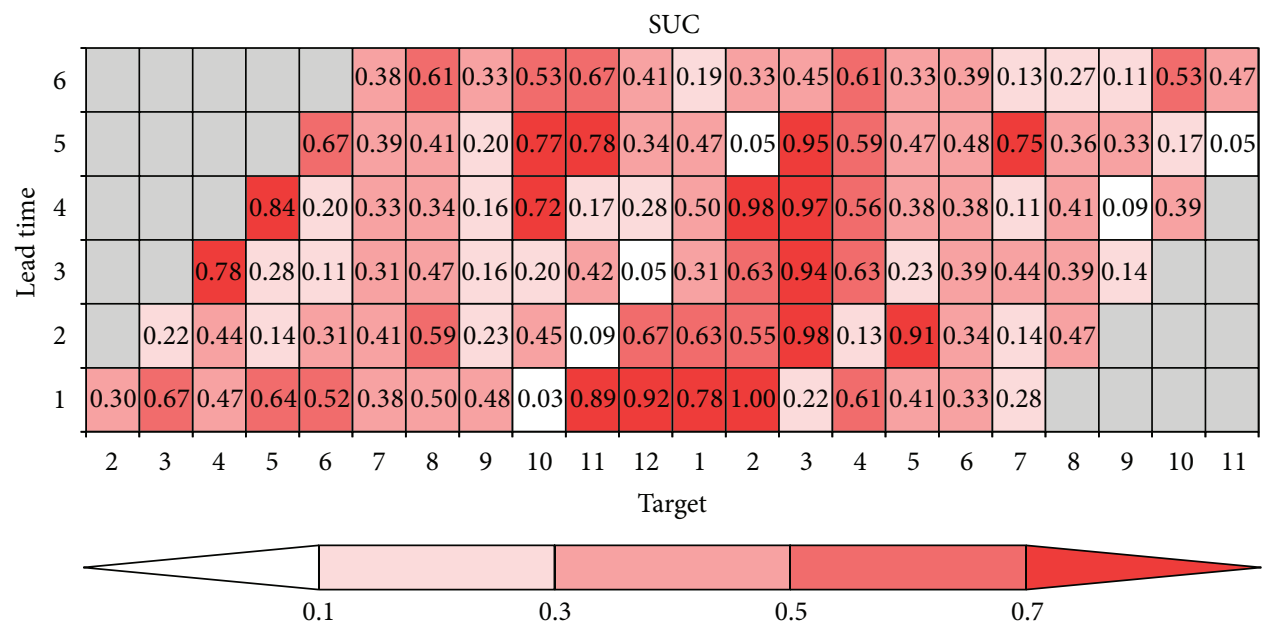

(c)

FIGURE 8: Skill scores (SS) for different lead times (vertical axis) and different target months (horizontal axis) for the CTL (a), BAS (b), and SUC (c) experiments.

scores (Figure 8, top). In the BAS experiment, RegCM_CFSv2 can better capture the observed terciles, especially for the Northern part of Vietnam (Figure 7, middle). However, the SS is still small, below 0.2 for most stations (Figure 8, middle). The SUC experiment gives evidence for improved skills of tercile prediction. With the SUC correction, the tercile forecast can capture most of the observed above-normal terciles reasonably well (Figure 7 , bottom). The SS values increase significantly from 0.3 to 0.6 regardless of the forecast lead time (Figure 8, bottom).

3.3. Prediction of Maximum and Minimum Temperature. Forecast errors of Tx for different lead times are shown in Figure 9. It can be seen that, similar to the $\mathrm{T} 2 \mathrm{~m}$, the forecasted Tx in the CTL experiment is affected by cold biases. At all lead times, most of the forecast errors (forecast minus 


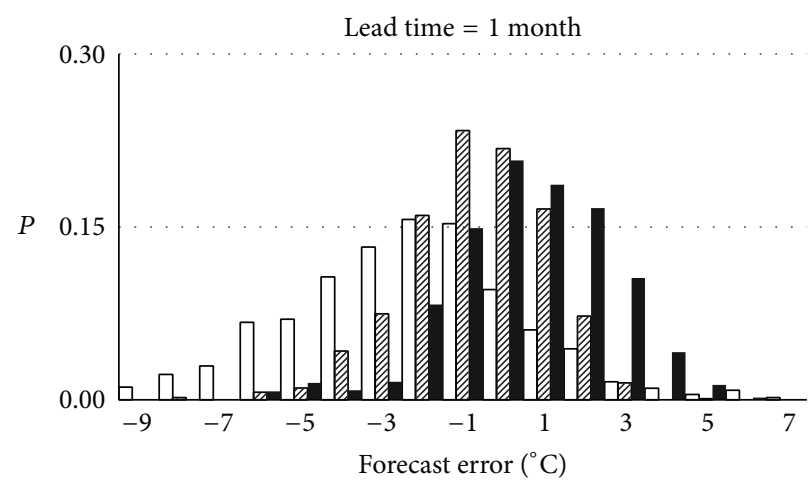

(a)

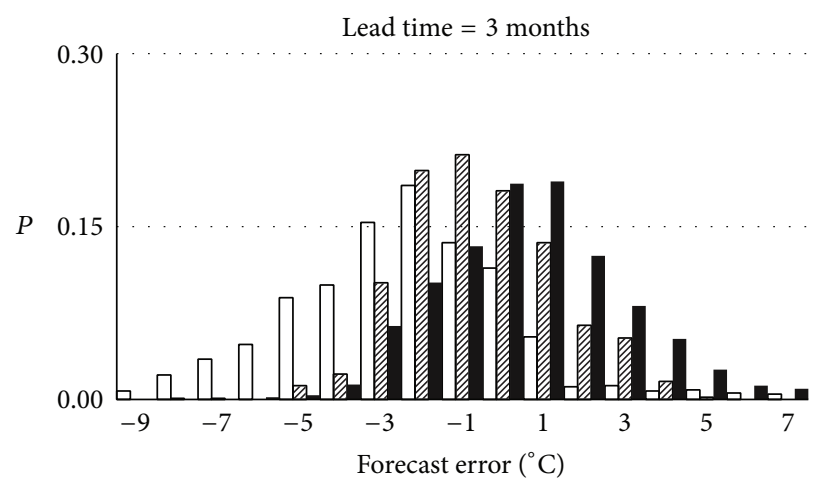

(b)

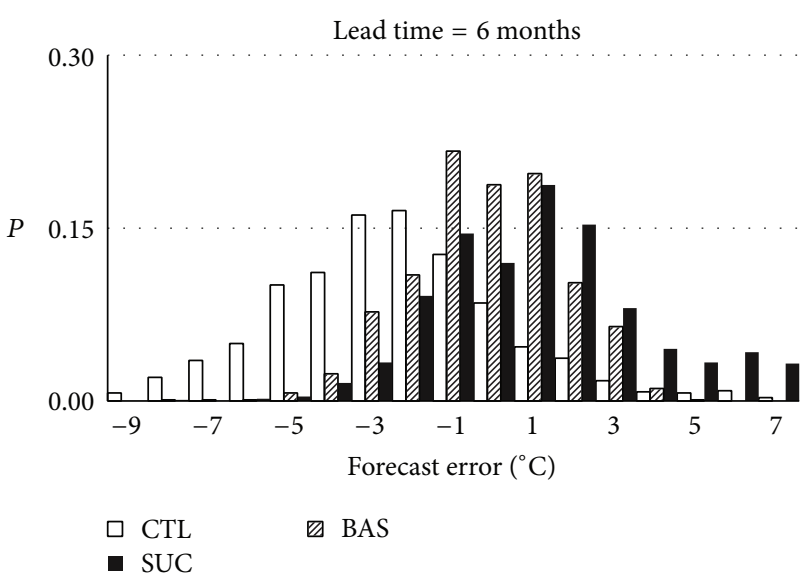

(c)

Figure 9: Frequency distributions $(P)$ of the Tx forecast errors $\left({ }^{\circ} \mathrm{C}\right)$ for lead times of 1 month (a), 3 months $(\mathrm{b})$, and 6 months (c).

observation) range from $-6.0^{\circ} \mathrm{C}$ to $-1.0^{\circ} \mathrm{C}$ (Figure 9, white bar). In the BAS experiment, the cold biases in Tx could be reduced (Figure 9, stippled bar). In the SUC, the accuracy has been further improved with errors ranging between $\pm 1.0^{\circ} \mathrm{C}$ (Figure 9, black bars). Although the errors are reduced in the SUC experiment, there is an increase in warm biases of forecasted Tx for lead times larger than three months (Figures 9(a)-9(c)).

The forecast errors of Tn in Figure 10 are similar to those of Tx. The CTL experiment shows significant cold biases of Tn with most values ranging from $-10.0^{\circ} \mathrm{C}$ to $-1.0^{\circ} \mathrm{C}$ (Figure 10 , white bars). In the BAS experiment, the errors are reduced, ranging from $-2.0^{\circ} \mathrm{C}$ to $+2.0^{\circ} \mathrm{C}$ (Figure 10 , stippled bars). The SUC experiment with lead times of 1 to 2 months shows errors ranging from $-1.0^{\circ} \mathrm{C}$ to $+1.0^{\circ} \mathrm{C}$. For forecast lead times greater than 2 months, the forecast errors show warm biases with values ranging from $2.0^{\circ} \mathrm{C}$ to $3.0^{\circ} \mathrm{C}$ (Figure 10, black bars).

\section{Summary and Conclusions}

Operational seasonal forecasts for Vietnam are based on statistical methods exclusively and are of limited usability and skill. In this study, we explore the skill of dynamical methods for the first time. The RegCM4.2 model has been used to perform seasonal prediction of mean, maximum, and minimum 2-m temperature from January 2012 to November 2013. The boundary conditions are from the NCEP Climate Forecast System. Both skills to predict the tercile probabilities and the values are analyzed. The RegCM_CFSv2 simulations were performed four times per month up to the next six months ahead. The results showed that without any bias correction, the RegCM_CFSv2 had little or no skill across Vietnam. After bias correction, the RegCM_CFSv2 predictions showed improved but still limited skills in the operational mode. Further improvements could be achieved by SUC experiment.

More detailed research studies are necessary to improve the skills of dynamical seasonal prediction for Vietnam. Since it is of crucial importance for agriculture, natural disaster prevention, and also water resource management in Vietnam, the predictability of rainfall will be focused in future studies.

\section{Conflict of Interests}

The authors declare that there is no conflict of interests regarding the publication of this paper. 


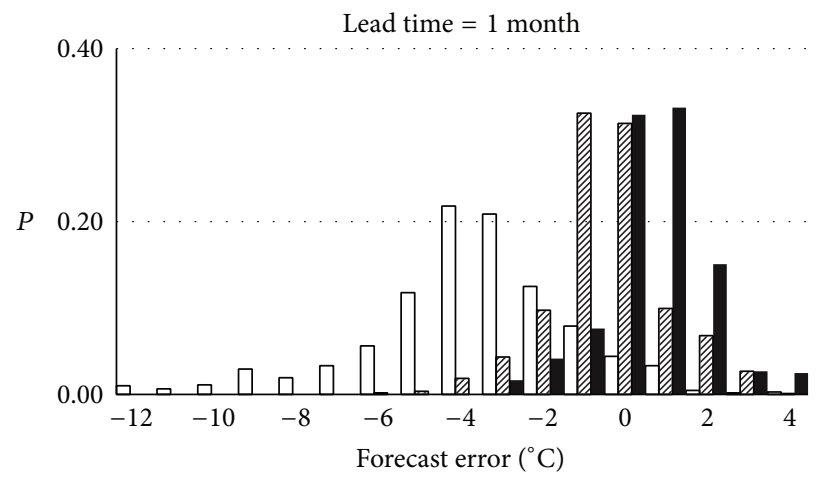

(a)

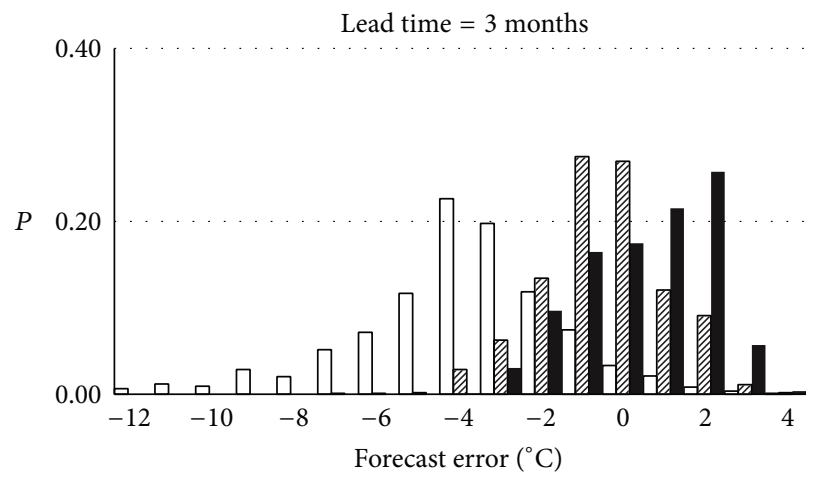

(b)

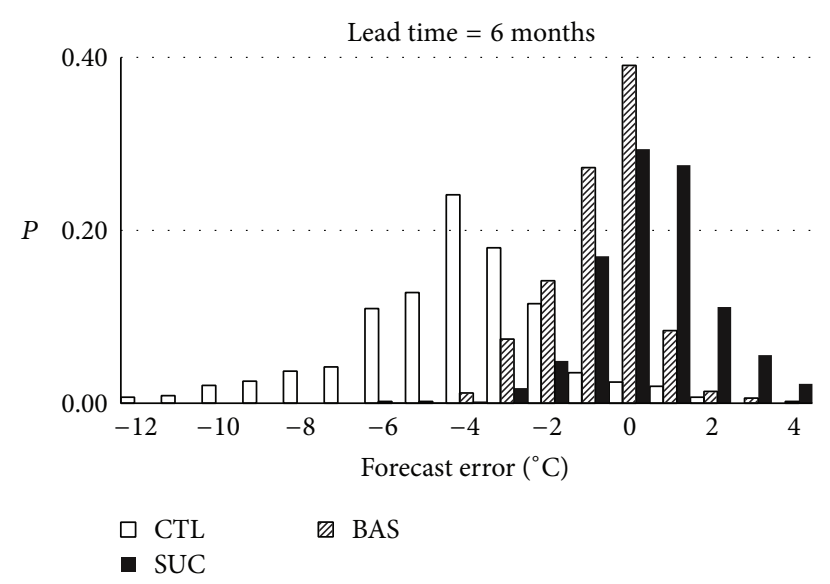

(c)

Figure 10: Same as Figure 9 but for $\operatorname{Tn}\left({ }^{\circ} \mathrm{C}\right)$.

\section{Acknowledgments}

This work was supported by the Vietnam Ministry of Science and Technology Foundation under the Project no. DT.NCCB-DHUD.2011-G/09. This work was also encouraged by the Management Board of the Danida 11-P04-VIE Project.

\section{References}

[1] S. Wang and J. Zhu, "A review on seasonal climate prediction," Advances in Atmospheric Sciences, vol. 18, no. 2, pp. 197-208, 2001.

[2] T. N. Stockdale, "An overview of techniques for seasonal forecasting," Stochastic Environmental Research and Risk Assessment, vol. 14, no. 4-5, pp. 305-318, 2000.

[3] H. Annamalai, J. Potemra, R. Murtugudde, and J. P. McCreary, "Effect of preconditioning on the extreme climate events in the tropical Indian Ocean," Journal of Climate, vol. 18, no. 17, pp. 3450-3469, 2005.

[4] P. B. Duffy, R. W. Arritt, J. Coquard et al., "Simulations of present and future climates in the western United States with four nested regional climate models," Journal of Climate, vol. 19, no. 6, pp. 873-895, 2006.

[5] P. J. Kloizbach and W. M. Gray, "Forecasting September Atlantic basin tropical cyclone activity," Weather and Forecasting, vol. 18, pp. 1190-1128, 2003.
[6] T. N. Krishnamurti, L. Stefanova, A. Chakraborty et al., "Seasonal forecasts of precipitation anomalies for North American and Asian Monsoons," Journal of the Meteorological Society of Japan Series 2, vol. 80, no. 6, pp. 1415-1426, 2002.

[7] F. J. Doblas-Reyes, R. Hagedorn, and T. N. Palmer, "Developments in dynamical seasonal forecasting relevant to agricultural management," Climate Research, vol. 33, no. 1, pp. 19-26, 2006.

[8] C. L. Castro, H.-I. Chang, F. Dominguez, C. Carrillo, J.-K. Schemm, and H.-M. H. Juang, "Can a regional climate model improve the ability to forecast the North American monsoon?" Journal of Climate, vol. 25, no. 23, pp. 8212-8237, 2012.

[9] X. Yuan and X. Z. Liang, "Improving cold season precipitation prediction by the nested CWRF-CFS system," Geophysical Research Letters, vol. 38, no. 2, Article ID L02706, 2011.

[10] S. Saha, S. Nadiga, C. Thiaw et al., "The NCEP climate forecast system," Journal of Climate, vol. 19, no. 15, pp. 3483-3517, 2006.

[11] B. P. Kirtman and D. Min, "Multimodel ensemble ENSO prediction with CCSM and CFS," Monthly Weather Review, vol. 137, no. 9, pp. 2908-2930, 2009.

[12] H.-M. Kim, P. J. Webster, J. A. Curry, and V. E. Toma, "Asian summer monsoon prediction in ECMWF System 4 and NCEP CFSv2 retrospective seasonal forecasts," Climate Dynamics, vol. 39, no. 12, pp. 2975-2991, 2012.

[13] H.-K. L. Drbohlav and V. Krishnamurthy, "Spatial structure, forecast errors, and predictability of the South Asian monsoon 
in CFS monthly retrospective forecasts," Journal of Climate, vol. 23, no. 18, pp. 4750-4769, 2010.

[14] K. P. Sooraj, H. Annamalai, A. Kumar, and H. Wang, "A comprehensive assessment of CFS seasonal forecasts over the tropics," Weather and Forecasting, vol. 27, no. 1, pp. 3-27, 2012.

[15] W. Wang, M. Chen, and A. Kumar, "An assessment of the CFS real-time seasonal forecasts," Weather and Forecasting, vol. 25, no. 3, pp. 950-969, 2010.

[16] Y. Ding, X. Shi, Y. Liu et al., "Multi-year simulations and experimental seasonal predictions for rainy seasons in China by using a nested regional climate model (RegCM_NCC) - part I: sensitivity study," Advances in Atmospheric Sciences, vol. 23, no. 3, pp. 323-341, 2006.

[17] A. Frumkin and V. Misra, "Predictability of dry season reforecasts over the tropical and the sub-tropical South American region," International Journal of Climatology, vol. 33, no. 5, pp. 1237-1247, 2013.

[18] D. N. Nguyen and T. H. Nguyen, Vietnam Climate and Climatic Resources, Agriculture Publisher, Hanoi, Vietnam, 2004 (Vietnamese).

[19] F. Giorgi, M. R. Marinucci, and G. T. Bates, "Development of a second-generation regional climate model (RegCM2) - part I: boundary-layer and radiative transfer processes," Monthly Weather Review, vol. 121, no. 10, pp. 2794-2813, 1993.

[20] J. S. Pal, E. E. Small, and E. A. B. Eltahir, "Simulation of regionalscale water and energy budgets: representation of subgrid cloud and precipitation processes within RegCM," Journal of Geophysical Research: Atmospheres, vol. 105, no. 24, pp. 2957929594, 2000.

[21] V.-T. Phan, T. Ngo-Duc, and T.-M. Ho, "Seasonal and interannual variations of surface climate elements over Vietnam," Climate Research, vol. 40, no. 1, pp. 49-60, 2009.

[22] T.-M. Ho, V.-T. Phan, N.-Q. Le, and Q.-T. Nguyen, "Extreme climatic events over Vietnam from observational data and RegCM3 projections," Climate Research, vol. 49, no. 2, pp. 87100, 2011.

[23] F. Giorgi, N. Elguindi, S. Cozzini, and G. Giuliani, Regional Climatic Model RegCM User's Guide Version 4.2, The Abdus Salam International Centre for Theoretical Physics, Trieste, Italy, 2011.

[24] F. Giorgi and C. Shields, "Tests of precipitation parameterizations available in latest version of NCAR regional climate model (RegCM) over continental United States," Journal of Geophysical Research: Atmospheres, vol. 104, no. D6, pp. 6353-6375, 1999.

[25] G. A. Grell, "Prognostic evaluation of assumptions used by cumulus parameterizations," Monthly Weather Review, vol. 121, no. 3, pp. 764-787, 1993.

[26] M. B. Sylla, A. T. Gaye, J. S. Pal, G. S. Jenkins, and X. Q. Bi, "High-resolution simulations of West African climate using regional climate model (RegCM3) with different lateral boundary conditions," Theoretical and Applied Climatology, vol. 98, no. 3-4, pp. 293-314, 2009.

[27] D. Martínez-Castro, R. P. da Rocha, A. Bezanilla-Morlot et al., "Sensitivity studies of the RegCM3 simulation of summer precipitation, temperature and local wind field in the Caribbean Region," Theoretical and Applied Climatology, vol. 86, no. 1-4, pp. 5-22, 2006.

[28] J. P. R. Fernandez, S. H. Franchito, and V. B. Rao, "Simulation of the summer circulation over South America by two regional climate models-part I: mean climatology," Theoretical and Applied Climatology, vol. 86, no. 1-4, pp. 247-260, 2006. 

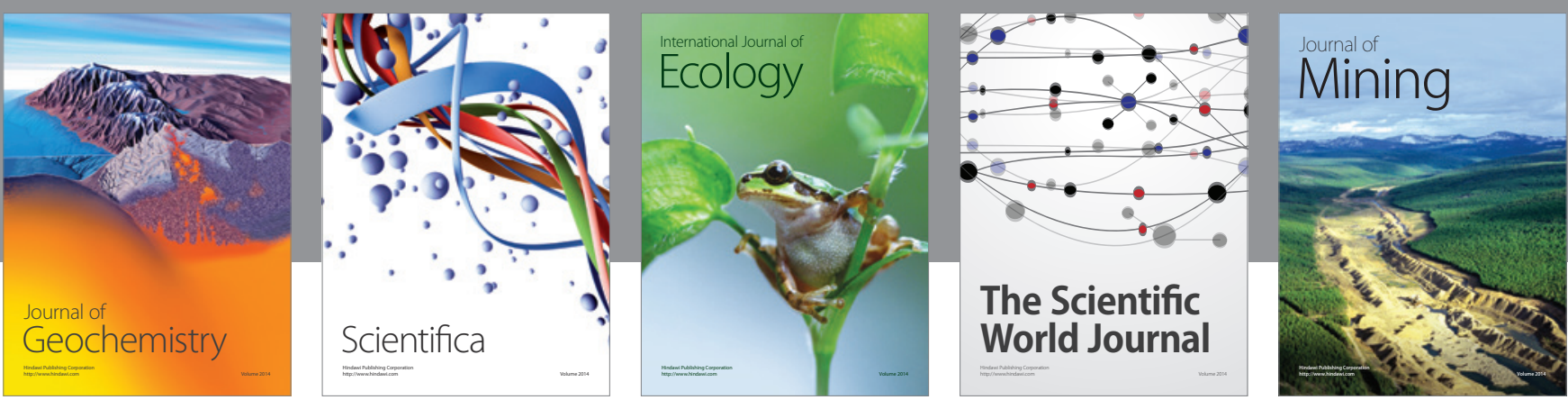

The Scientific World Journal
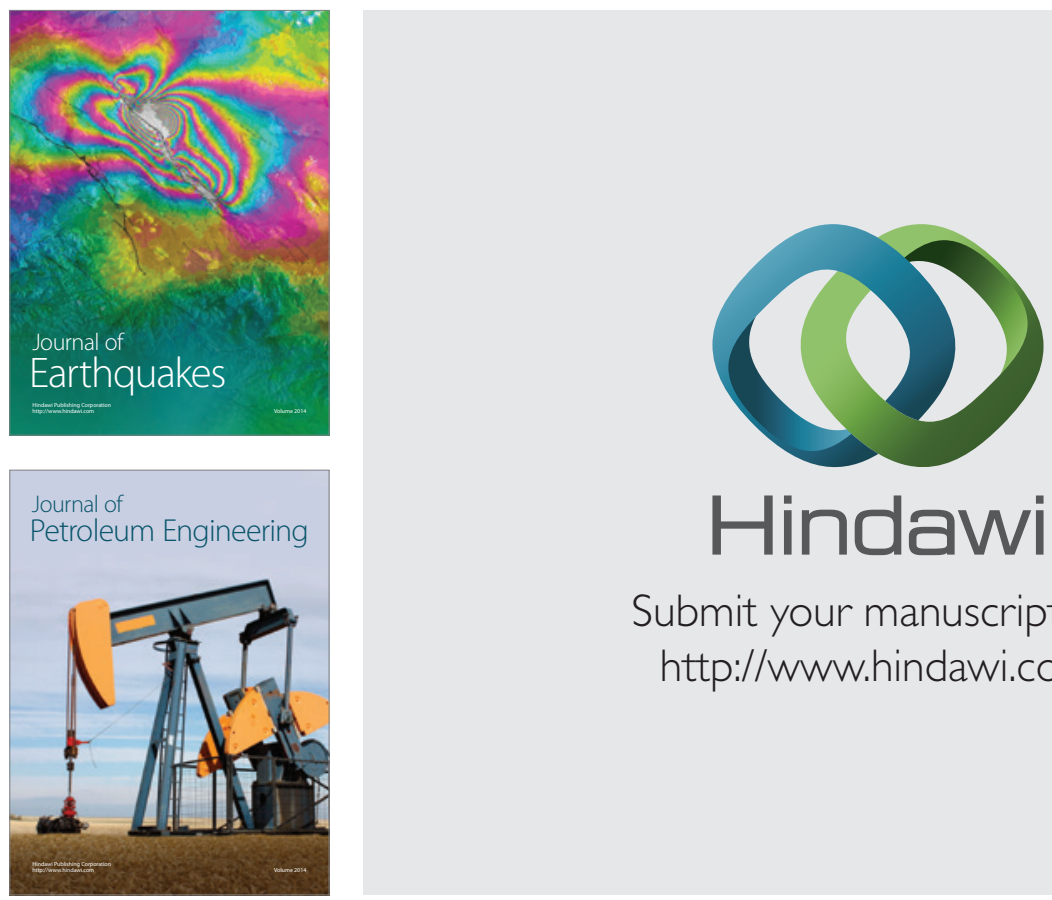

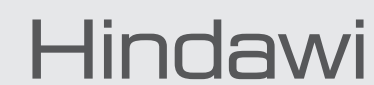

Submit your manuscripts at

http://www.hindawi.com
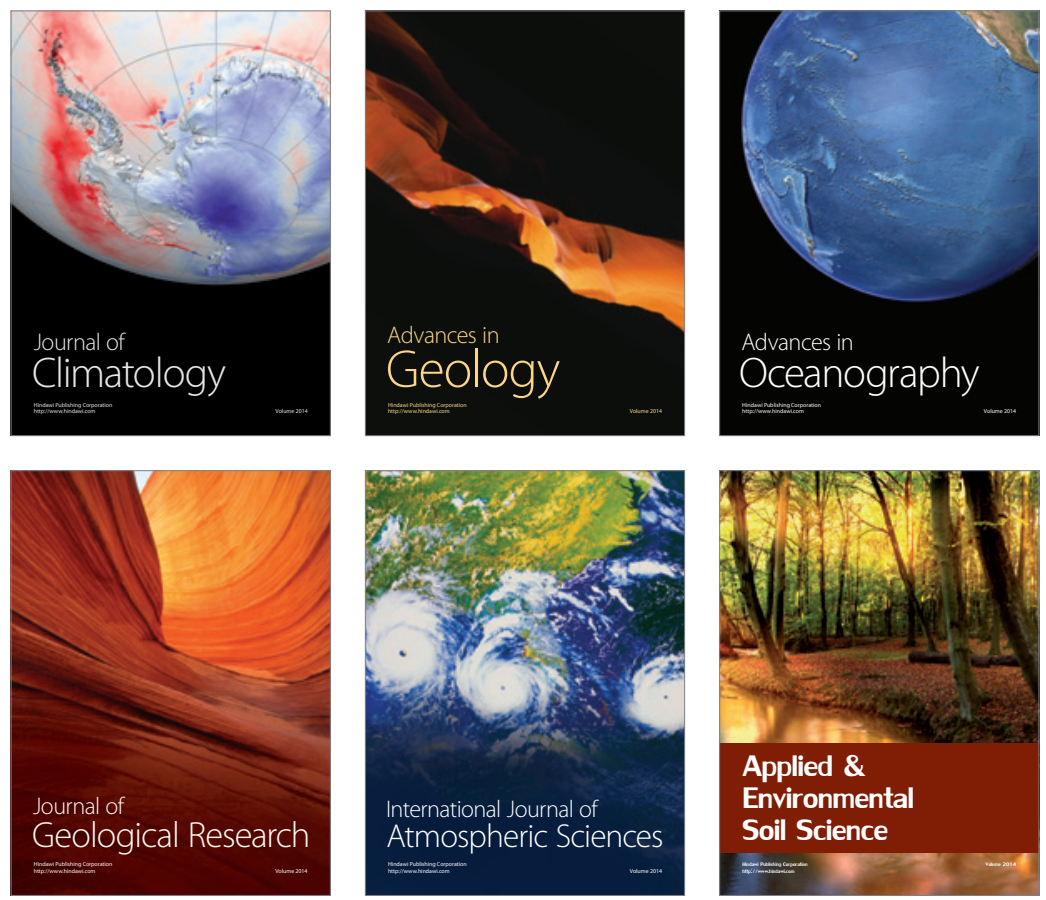
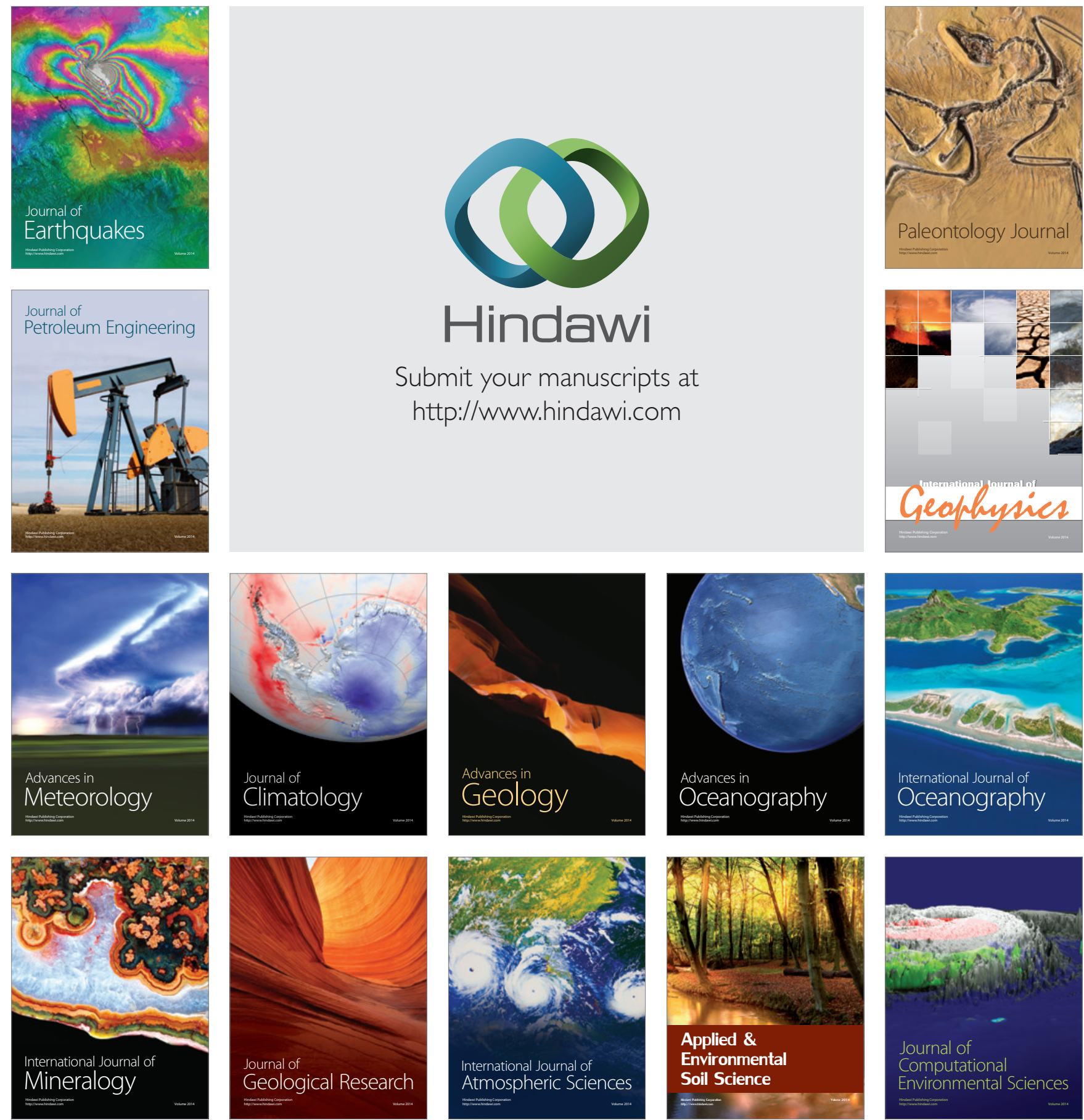